\title{
Correlation of Predictor Variables to Squalene Content in Olive Fruits Using Multivariate Statistical Analysis
}

\author{
Hakan Cetinkaya $^{1^{*}}$ \\ ${ }^{1}$ Department of Horticulture, Faculty of Agriculture, Kilis 7 Aralık University, 79000, Kilis, TURKEY
}

\begin{abstract}
The present study was designed to examine the correlation of some predictor variables including $\mathrm{pH}$, organic matter $(\mathrm{OM})$, lime $(\mathrm{L})$, phosphorus $(\mathrm{P})$, potassium $(\mathrm{K})$ and total salt (TS) content of soils of olive orchards to squalene content of olive fruits. Multiple linear regression analysis was used to model the relationship between explanatory variables $(\mathrm{pH}, \mathrm{OM}, \mathrm{L}, \mathrm{P}, \mathrm{K}$ and $\mathrm{TS}$ ) and responses variable (squalene content) by fitting a linear equation to observed data. The olive fruits (Kilis Yaglik cv.) were sampled from tendifferent locations. The soil characteristics of the sampling sites were determined. Oil extraction was carried out in similar industrial extraction conditions using an oleodosor system. Accordingly, $\mathrm{pH}(\mathrm{p}=0.596), \mathrm{OM}(\mathrm{p}=0.359), \mathrm{L}(\mathrm{p}=0.490), \mathrm{P}(\mathrm{p}=0.127)$, $K(p=0.265)$ and TS $(p=0.572)$ were not individually statistical significant but their interaction was significant $(p=0.006)$. Standardizing the olive oil quality is not easy at all due to complex and variable environmental conditions. Along with the results herein, the factors themselves were not significant but their complex interaction was significant.
\end{abstract}

Keywords: Squalene, Olive oil, Soil characteristics, Kilis Yaglik cv., Multivariate statistical analysis.

\section{INTRODUCTION}

Olea europaea L. (olive), which its fruit and oil have a major agricultural importance in Turkey, is of significant crop especially in Mediterranean countries. The oil obtained from olive fruits have been used not only nutrient and as a flavor enhancer in Mediterranean dishes, but also a medicine because of having essential roles for human health. The pharmaceutical value of olive oil is related to its biochemical content. Mainly four chemical sources: polyphenols, carotenoids, mono-unsatured fatty acids and squalene are functional bioactives in olive oil particularly for pharmaceutical affects. ${ }^{1}$ Squalene is a polyunsaturated triterpene widely prevalent in living being, especially among wheat germ, rice bran, shark liver oil and olives. ${ }^{2}$ Squalene in olive oil is in general considerably high as compared to other oils. ${ }^{34}$ Because of its potential pharmaceutical impacts researchers have been interested in production and biochemistry of squalene in recent years. It has various favourable effects as a nutrient, preventive and therapeutic medicine. ${ }^{5,6,7} \mathrm{~A}$ number of various studies indicate that squalene has important pharmaceutical activity like preventation cardiovascular diseases, strengthen the immune system, interference many cancer types, improving antitumor action of chemotherapeutic agents, protection the skin by scavenging singlet oxygen generated by UV light, anti-aging, reducing blood cholesterol, inhibition the development of tumors. ${ }^{5-8,9,10}$ The olive oil contains about $0.2-0.7 \%$ squalene. Humans absorbs $60 \%$ of squalene from food and the average intake of squalene is $30 \mathrm{mg} /$ day. ${ }^{11}$ Plant growth may be positively or adversely influenced in growing area by a num-
DOI: 10.5530/ijper.51.3s.39 Correspondence: Hakan Cetinkaya, Department of Horticulture, Faculty of Agriculture, Kilis 7 Aralik University, 79000 , Kilis, TURKEY

Fax:+903488139324 Phone no:+903488142666 E-Mail: hcetinkaya67@gmail. com 
ber of factors. In this study, variation in the squalene was examined with soil characteristics. Also, the size of variation by soil conditions where the sampling done, and evaluations were compared based on the regression and linear trend analysis.

\section{MATERIAL AND METHODS}

\section{Analysis of soil characteristics}

Total dissolved salts by Saturation Extract Method, calcium carbonate $\left(\mathrm{CaCO}_{3}\right)$ contents by Scheibler Calcimeter, organic matter by a modification of the Walkley and Black method, soil potassium content by flame photometer were determined for 10 locations. ${ }^{12}$

\section{Oil extraction and squalene analysis}

The olive fruits were harvested from the same aged trees and cultivar (Kilis Yaglik cv.) in mid-December. The oils were extracted from olive fruits with n-hexane for four hours using a Soxhlet Extraction Apparatus (Thermal). The squalene analyses were conducted according to the official method COI/T.20/Doc.no.24 2001. Gas chromatography with flame ionization detector (GC-FID) analyses of squalene methyl esters was carried out on a Shimadzu gas chromatography (GC-2010 series) equipped with an Supelco SP 2380 fused silica capillary column (100 m, $0.25 \mathrm{~mm}$ i.d., $0.2 \mu \mathrm{m}$ film thickness).

\section{Statistical analysis}

SPSS statistical program was used to determine statistical significance levels by employing the independent one-way ANOVA followed by Duncan multiple range test and the differences between individual averages were considered to be statistically important at $\mathrm{p}<0.05$. The results were expressed as mean.

\section{RESULTS}

Squalene content of olive oils and soil characteristics from 10 locations have been shown Table 1. Squalene contents varied at different locations. Accordingly, the highest squalene was obtained from locations 4 and 9 (Table 2). According to the regression coefficients, soil characteristics, in order of priorities, total salt, $\mathrm{pH}$, organic matter, phosphorus and potassium have influenced the squalene content of oil. While total salt and $\mathrm{pH}$ has a greater effect on squalene content, other factors have been less effective. Along with the results herein, the factors themselves were not significant but their complex interaction was significant. Accordingly, $\mathrm{pH}$ ( $p=0.596), O M(p=0.359), L(p=0.490), P(p=0.127)$, $\mathrm{K}(\mathrm{p}=0.265)$ and TS $(\mathrm{p}=0.572)$ were not individually statistical significant but their interaction was significant $(p=0.006)$ (Table 3). According to the results of the regression analysis, the mathematical expression of the effect of soil properties on the squalene content is shown below:

Squalene content $(\%)=(1.554)+(-0.106 x \mathbf{p H})+(-0.003 \mathrm{x}$ Lime $)+(1.821 \times$ Total Salt $)+(0.027 x \mathbf{P})+(0.001 \times \mathbf{K})+$ (-0.024xOrganic Matter)

\begin{tabular}{|c|c|c|c|c|c|c|c|}
\hline \multicolumn{7}{|c|}{ Table 1: Squalene content of olive oil and soil characteristics in ten location } \\
\hline Location & $\begin{array}{c}\text { Squalene } \\
\%\end{array}$ & $\mathbf{p H}$ & $\begin{array}{c}\text { Lime (\%) } \\
\mathbf{C a C O}_{3}\end{array}$ & $\begin{array}{c}\text { T. Salt } \\
\%\end{array}$ & $\begin{array}{c}\mathbf{P}(\%) \\
\mathbf{P}_{\mathbf{2}} \mathbf{O}_{\mathbf{5}}\end{array}$ & $\mathbf{K}\left(\mathbf{k g ~ d a}^{-1}\right) \mathbf{K}_{\mathbf{2}} \mathbf{O}$ & $\mathbf{O}_{\text {O. Matter \% }}$ \\
\hline 1 & 0.80 & 7.89 & 16.88 & 0.016 & 1.77 & 88.75 & 2.66 \\
\hline 2 & 0.75 & 7.79 & 30.00 & 0.032 & 2.40 & 75.00 & 3.59 \\
\hline 3 & 0.69 & 7.87 & 45.56 & 0.002 & 0.70 & 48.58 & 2.48 \\
\hline 4 & 1.04 & 7.68 & 11.56 & 0.031 & 3.61 & 92.00 & 0.62 \\
\hline 5 & 0.89 & 7.69 & 11.48 & 0.033 & 2.52 & 105.60 & 3.16 \\
\hline 6 & 0.79 & 7.83 & 23.31 & 0.032 & 5.04 & 67.50 & 2.48 \\
\hline 7 & 0.88 & 7.87 & 22.91 & 0.037 & 4.29 & 22.50 & 2.66 \\
\hline 8 & 0.95 & 8.20 & 4.55 & 0.037 & 5.61 & 95.28 & 1.44 \\
\hline 9 & 0.97 & 8.03 & 16.67 & 0.023 & 7.28 & 80.75 & 4.77 \\
\hline 10 & 0.72 & 7.67 & 22.91 & 0.025 & 1.95 & 40.00 & 2.11 \\
\hline
\end{tabular}

\begin{tabular}{|c|c|c|c|c|c|c|c|c|c|c|}
\hline Locations & 1 & 2 & 3 & 4 & 5 & 6 & 7 & 8 & 9 & 10 \\
\hline Squalene(\%) & $\begin{array}{l}0.8 \\
\text { b-e }\end{array}$ & $\begin{array}{l}0.75 \\
\text { c-e }\end{array}$ & $\begin{array}{l}0.69 \\
e^{0}\end{array}$ & $\begin{array}{l}1.04 \\
a\end{array}$ & $\begin{array}{l}0.89 \\
a-c\end{array}$ & $\begin{array}{l}0.79 \\
\text { b-e }\end{array}$ & $\begin{array}{l}0.88 \\
\text { a-d }\end{array}$ & $\begin{array}{l}0.95 \\
\text { ab }\end{array}$ & $\begin{array}{l}0.97 \\
a\end{array}$ & $\begin{array}{l}0.72 \\
\text { de }\end{array}$ \\
\hline
\end{tabular}


Table 3: Coefficients for squalene content in olive oil.

\begin{tabular}{|c|c|c|c|c|c|}
\hline & \multicolumn{2}{|c|}{$\begin{array}{c}\text { Unstandardized } \\
\text { Coefficients }\end{array}$} & $\begin{array}{c}\text { Standardized } \\
\text { Coefficients }\end{array}$ & t & Sig. \\
\hline & B & Std. Error & Beta & & \\
\hline (Constant) & 1,554 & 1.536 & & 1.011 & 0.322 \\
\hline $\mathrm{pH}$ & -0.106 & 0.197 & -0.100 & -0.537 & 0.596 \\
\hline Lime & -0.003 & 0.004 & -0.214 & -0.701 & 0.490 \\
\hline Total salt & 1.821 & 3.178 & 0.117 & 0.573 & 0.572 \\
\hline $\mathrm{P}$ & 0.027 & 0.017 & 0.395 & 1.585 & 0.127 \\
\hline K & 0.001 & 0.001 & 0.242 & 1.142 & 0.265 \\
\hline Organic Matter & -0.024 & 0.025 & -0.157 & -0.935 & 0.359 \\
\hline
\end{tabular}

\begin{tabular}{|c|c|c|c|c|c|c|c|}
\multicolumn{6}{|c|}{ Table 4: Correlations between Squalene content and soil characteristics. } \\
\hline & Squalene & pH & Lime & T. Salt & P & K & O. Matter \\
\hline Squalene & 1 & 0.124 & $-0.667^{* *}$ & $0.472^{* *}$ & $0.510^{* *}$ & $0.412^{*}$ & -0.19 \\
\hline pH & 0.124 & 1 & -0.147 & -0.021 & $0.543^{* *}$ & 0.037 & 0.185 \\
\hline Lime & $-0.667^{* *}$ & -0.147 & 1 & $-0.599^{* *}$ & $-0.557^{* *}$ & $-0.578^{* *}$ & 0.24 \\
\hline Total Salt & $0.472^{* *}$ & -0.021 & $-0.599^{* *}$ & 1 & $0.454^{*}$ & 0.09 & -0.153 \\
\hline P & $0.510^{* *}$ & $0.543^{* *}$ & $-0.557^{* *}$ & $0.454^{*}$ & 1 & 0.089 & 0.153 \\
\hline K & $0.412^{*}$ & 0.037 & $-0.578^{* *}$ & 0.09 & 0.089 & 1 & -0.025 \\
\hline O. Matter & -0.19 & 0.185 & 0.24 & -0.153 & 0.153 & -0.025 & 1 \\
\hline
\end{tabular}

*. Correlation is significant at the 0.05 level (2-tailed).

**. Correlation is significant at the 0.01 level (2-tailed).

In comparison with correlation of squalene content and soil characteristics at different locations, the contents of squalene determined the highest correlation with lime and followed by phosphorus, total salt and potassium as soil characteristics, respectively. Factors have similar relationships among each other (Table 4).

\section{DISCUSSIONS}

The chemical and physical properties of the soil influence plant growth, development and subsequently main primary and secondary metabolite production, secretion and accumulation. It is worth to note that the produced metabolites transport among the organs of the plants is also significantly affected by soil properties. The profile of the oils was influenced by the different ecological and topographical conditions, supplying additional information about the climatic conditions and its impact on the oil quality. Many agronomical and soil factors effect composition of olive oil, such as the climate, cultivar, degree of maturation and harvest time, irrigation, the place of cultivation, crop season, the production process and type. ${ }^{13,14,15,16,17}$

\section{CONCLUSION}

Fatty acids, phenolic compounds and other minor compounds indicate the quality of olive oil. Standardizing the olive oil quality is not easy at all due to complex and variable environmental conditions. Ecological factors influence the amount of squalene in olive oil. For olive quality and squalene suitable edaphic factors may be chosen.

\section{ACKNOWLEDGEMENT}

The author is thankful to Dr. Muhittin Kulak from Biology Department for multivariate statistical analyses

\section{CONFLICT OF INTEREST}

The author declares that they have no conflict of interest.

\section{ABBREVIATION USED}

OM: Organic Matter; L: Lime; P: Phosphorus; K: Potassium; TS: Total Salt; GC-FID: Gas Chromatography with Flame Ionization Detector; m: meter; mm: millimeter; $\mu \mathrm{m}$ : micrometer; p: significance value. 


\section{REFERENCES}

1. Giuffrida D, Salvo F, Salvo A, Cossignani L, Dugo G. Pigments profile in monovarietal virgin olive oils from various Italian olive varieties. Food Chemistry. 2011;124(3):1119-23.

2. Spanova M, Daum G. Squalene-biochemistry, molecular biology, process biotechnology, and applications. European Journal of Lipid Science Technology 2011;113(10):1299-320.

3. Grigoriadou D, Androulaki A, Psmiadou E, Tsimidou MZ. Solid phase extraction in the analysis of squalene and tocopherols in olive oil. Food Chemistry. 2007;105(2):675-80

4. Reddy LH, Couvreur P. Squalene: a natural triterpene for use in disease management and therapy. Advanced Drug Delivery Reviews. 2009;61(15):1412-26.

5. Ronco AL, Stefani ED. Squalene: a multi-task link in the crossroads of cancer and aging. Functional Foods in Health and Disease. 2013;3(12):462-76.

6. Ghimire GP, Thuan NH, Koirala N, Sohng JK. Advances in biochemistry and microbial production of squalene and its derivatives. Journal of Microbiology and Biotechnology. 2016;26.441-51.

7. Salvo A, La Torre GL, Rotondo A, Mangano V, Casale KE, Pellizzeri V, et al. Determination of Squalene in Organic Extra Virgin Olive Oils (EVOOs) by UPLC/PDA Using a Single-Step SPE Sample Preparation. Food Analytical Methods. 2016;1-9.

8. Ghanbari R, Anwar F, Alkharfy KM, Gilani AH, Saari N. Valuable nutrients and functional bioactives in different parts of olive (Olea europaea L.)-A review. International Journal of Molecular Sciences. 2012;13(3):3291-340.
9. Owen RW, Haubner R, Würtele GW, Hull WE, Spiegelhalder B, Bartsch H. Olives and olive oil in cancer prevention. European Journal of Cancer Prevention. 2004;13(4):319-26.

10. Naziri E, Mantzouridou F, Tsimidou MZ. Enhanced squalene production by wild-type Saccharomyces cerevisiae strains using safe chemical means. Journal of Agr and Food Chem. 2011;59(18):9980-9.

11. Saitta M, La Torre GL, Potortì AG, Di Bella G, Dugo G. Polyphenols of pistachio (Pistacia vera L.) oil samples and geographical differentiation by principal component analysis. Journal of American Oil Chemists' Society.2014;91(9):1595-603

12. Kacar B, Inal A. Plant analysis. Nobel Press 2008;1241:891.

13. Tura D, Gigliotti C, Pedo S, Failla O, Bassi D, Serraiocco A. Influence of cultivar and site of cultivation on levels of lipophilic and hydrophilic antioxidants in virgin olive oils (Olea Europea L) and correlations with oxidative stability. Scientia Horticulturae. 2007;112(1):108-19.

14. Ocakoglu D, Tokatli F, Ozen B, Korel F. Distribution of simple phenols, phenolic acids and flavonoids in Turkish monovarietal extra virgin olive oils for two harvest years. Food Chem. 2009;113(2):401-10.

15. Sakouhi F, Herchi W, Sbei K, Absalon C, Boukhchina S. Characterization and accumulation of squalene and n-alkanes in developing Tunisian Olea europaea L. fruits. International Journal of Food Science and Technology. 2011:46(11):2281-6.

16. Kesen S, Kelebek H, Selli S. LC-ESI-MS Characterization of phenolic profiles Turkish olive oils as influenced by geographic origin and harvest year. Journal of American Oil Chemists' Society 2014;91(3):385-94.

17. Cetinkaya H, Kulak M. Soil Characteristics Influence The Fatty Acid Profile Of Olive Oils. Scientific Papers Series B Horticulture. 2016;60:53-7.

\section{PICTORIAL ABSTRACT}
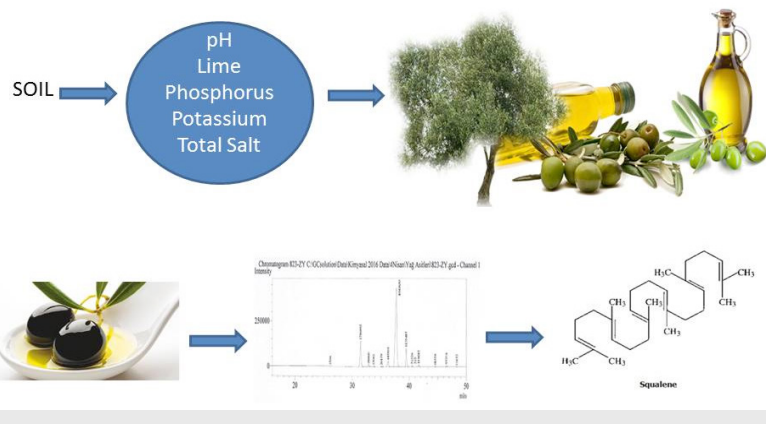

\section{SUMMARY}

- Influence of soil characteristics including $\mathrm{pH}$, organic matter (OM), lime (L), phosphorus (P), potassium (K) and total salt (TS) on squalene content of olive fruits have been determined

- Oil has extracted from Kilis Yaglik cv. olive fruits sampled from different location

- Squalene content $(\%)=(1.554)+(-0.106 \times \mathrm{pH})$ $+(-0.003 \times L)+(1.821 \times$ Total Salt $)+(0.027 \times P)$ $+(0.001 \times K)+(-0.024 x$ OM)

- The factors themselves were not significant but their complex interaction was significant.

\section{ABOUT AUTHORS}

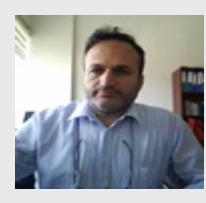

Dr. Hakan Cetinkaya: He is assistant professor at the Agriculture Faculty, Horticulture Department. His research area of interest is plant physiology, horticulture, fruits, olive and pistachio. Also he has researches on seconder metabolites of plants in abiotic stress conditions.

Cite this article: Cetinkaya H. Correlation of Predictor Variables to Squalene Content in Olive Fruits Using Multivariate Statistical Analysis. Indian J of Pharmaceutical Education and Research. 2017;51(3):S323-26.
} 